\title{
CONF-970806-- 1
}

\section{LA-UR- $9 \%$ \% \\ Title: Vanadium-Spinel Composites for Structural Applications in Hostile Environments}

Author(s):

R. B. Schwarz, CMS

C. J. Wetteland, MST-4

T. D. Shen, CMS

E. Ustundag, MST-4

K. E. Sickafus, MST-4

\section{RECEIVED \\ MAY 051997 \\ O. STI}

\section{Submitted to:}

\section{Los Alamos}

NATIONAL LABORATORY
To be presented at the Eleventh International Conference on the Strength of Materials, Prague, Czech Republic, August 25-29, 1997 to be published in Journal of Materials Science and Engineering A
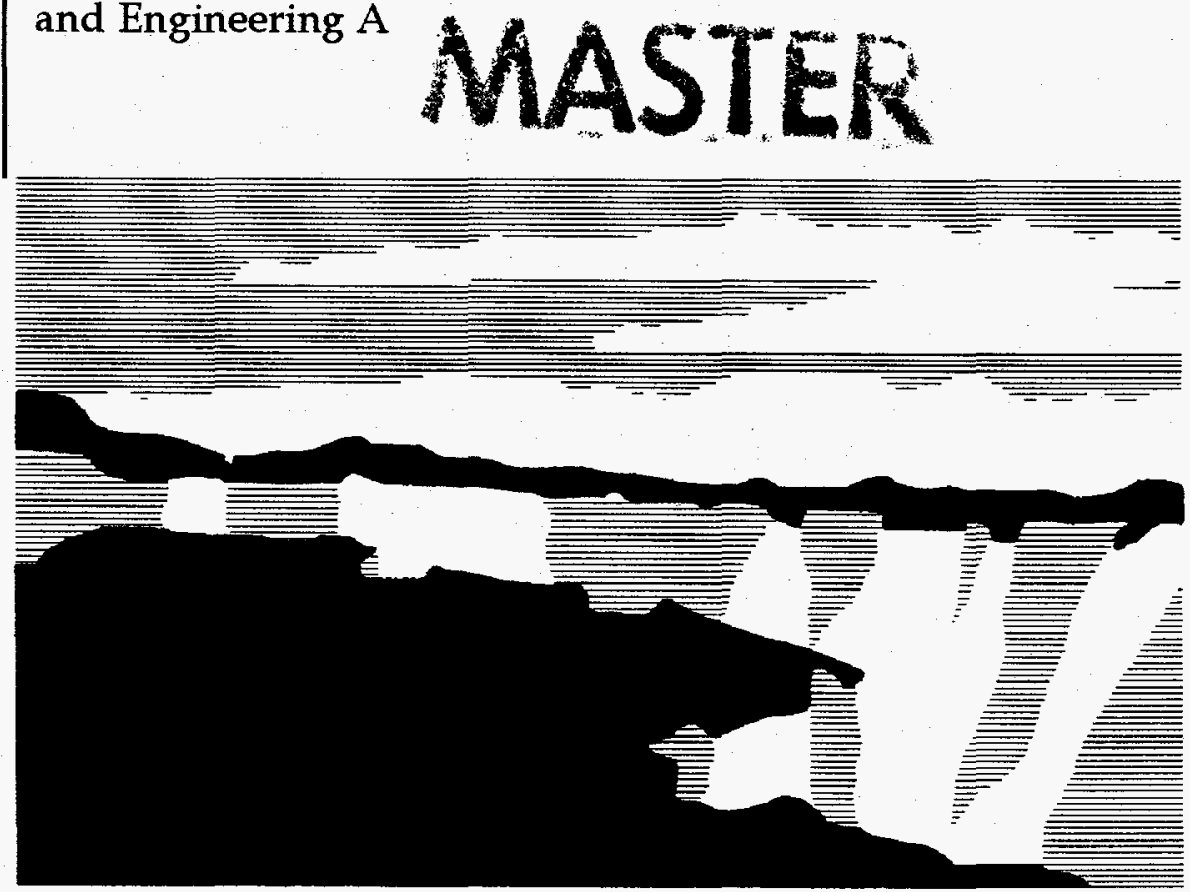

Los Alamos National Laboratory, an aftirmative action/equal opportunity employer, is operated by the University of California for the U.S. Department of Energy under contract W-7405-ENG-36. By acceptance of this article, the publisher recognizes that the U.S. Government retains a nonexclusive, royalty-free license to publish or reproduce the published form of this contribution, or to aliow others to do so, for U.S. Government purposes. The Los Alamos National Laboratory requests that the publisher identify this article as work performed under the auspices of the U.S. Department of Energy.

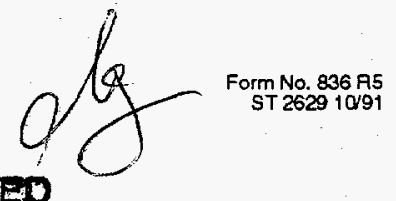




\section{DISCLAMMER}

Portions of this document may be illegible in electronic imsge products. Images are produced from the best available original document. 


\title{
Vanadium-Spinel Composites for Structural Applications in Hostile Environments
}

\author{
R. B. Schwarz, C. J. Wetteland, T. D. Shen, E. Ustundag, K. E. Sickafus
}

Los Alamos National Laboratory

Center for Materials Science and MST-4; Mail Stop K-765

Los Alamos, NM 87545, USA

\begin{abstract}
Vanadium-spinel composites are promising materials for structural applications in radiation environments. Powders of two Vanadium-spinel composites, $20 / 80$ vol. \%, were prepared by (a) ball milling mixtures of vanadium and spinel powders (alloy VSLP) and (b) through a selfsustained reaction synthesis of vanadium, $\mathrm{MgO}$, and $\mathrm{Al}$ powders (alloy VSHP). These powders were consolidated by hot isostatic pressing. Most of the $\mathrm{V}$ and spinel domains in the the compacts are sub-micron in size. The compacts have $K_{\mathrm{c}}$ toughness values of 3.9 , about three times the toughness obtained by hipping mixtures of commercial powders.
\end{abstract}

Keywords: composites, radiations resitance, toughness

\section{INTRODUCTION}

In 1996, Sickafus et al. [1] proposed that a composite of vanadium metal and $\mathrm{MgAl}_{2} \mathrm{O}_{4}$ spinel could potentially be a good candidate for structural applications in a deuterium-tritium magnetic fusion reactors. A simple analysis of the published properties of $\mathrm{V}$ and $\mathrm{MgAl}_{2} \mathrm{O}_{4}$ [1] suggested that the vanadium-spinel composite should have a number of attractive properties: good radiation resistance (e.g., absence of volume swelling during particle irradiation); high melting point and creep resistance, good thermal shock/fatigue resistance (the thermal expansion coefficients of $\mathrm{V}$ and $\mathrm{MgAl}_{2} \mathrm{O}_{4}$ are well matched); good thermal conductivity, especially if the vanadium phase in the composite is continuous; and good toughness and strength: Preliminary 
tests showed that spinel bonds readily to metals and this should lead to both high hardness and toughness. These parameters, however, are strongly related to the microstructure. To test these predictions, Ustundag et al. [2] fabricated three vanadium-spinel composites at the volume ratio $40 / 60,50 / 50$, and $60 / 40$. These composites were prepared by mixing commercial vanadium and spinel powders and consolidating the mixture by hot pressing in graphite dies. The vanadium powder had an average particle size in the range 5-15 $\mu \mathrm{m}$ (including particles as large as $45 \mu \mathrm{m}$ ) whereas the spinel powder had an average particle size of about $10 \mu \mathrm{m}$. The properties of these compacts (density, microstructure, hardness, coefficient of thermal expansion, and toughness) were measured [2]. A sample of the 50/50 V/spinel composite was also irradiated in situ at $20 \mathrm{~K}$ with $1.5 \mathrm{MeV} \mathrm{Xe}$ ions to a fluence of $5.0 \times 10^{15}$ ions $\mathrm{cm}^{-2}$. All the grains in the sample retained their crystal structure for an ion dose that corresponds to approximately 5 dpa at a depth of $50 \mathrm{~nm}$ in spinel and $8.5 \mathrm{dpa}$ in vanadium. The only measured property that did not reach expectations was the fracture toughness, which ranged from 2.7 to $3.3 \mathrm{MPa} \mathrm{m}{ }^{1 / 2}$. The observed easy fracturing of the $V$ phase suggested that it may contain impurities, notably oxygen which, when present even at the ppm level, can drastically raise the ductile-to-brittle transition temperature of vanadium.[3] Another undesirable characteristic of these alloys was the rather large grain size of the constituents. It was speculated that a finer domain two-phase alloy would also increase the fracture toughness by blunting the crack propagation.

The goal of the present work was to produce a fine-structure composite of vanadium and spinel using mechanical alloying (MA), followed by hot isostatic pressing. By starting from pure and dried powders, we expected to obtain a lower oxygen content in the sintered $\mathrm{V}$ phase. 


\section{EXPERIMENTAL PROCEDURE}

Two vanadium-spinel composites, $20 / 80 \%$ by volume, denoted VSLP and VSHP, were prepared by different methods. The VSLP alloy was prepared from commercial vanadium powder (-325 mesh, $99.5 \%$ pure from Aldrich, Milwaukee, WI) and commercial $\mathrm{MgAl}_{2} \mathrm{O}_{4}(99 \%$ pure, from ALCOA, Bauxite, AR). A 5-gram mixture of these powders was vacuum dried at $150^{\circ} \mathrm{C}$. The mixture was then mechanically alloyed for $10 \mathrm{~h}$ in a SPEX 8000 shaker mill [Edison, NJ], using a tungsten carbide vial and a single 12-gram ball. The ball mill was located inside a glovebox which contains $\mathrm{Ar}$ gas with less than $1 \mathrm{ppm} \mathrm{O}_{2}$ and water vapor.

The VSHP alloy was prepared by a reaction synthesis route starting from a mixture of $\mathrm{V}_{2} \mathrm{O}_{5}, \mathrm{MgO}$, and metallic aluminum in the molar ratio 3:5:10. A 5-gram charge of these powders was dried in vacuum and was then mechanically alloyed in the same SPEX mill. The three components react according to $3 \mathrm{~V}_{2} \mathrm{O}_{5}+5 \mathrm{MgO}+10 \mathrm{Al} \rightarrow 6 \mathrm{~V}+5 \mathrm{MgAl}_{2} \mathrm{O}_{4}$. Figure 1 shows $\mathrm{x}$-ray diffraction patterns of the initial powder mixture and after various milling times. It is clear that the reaction described by Eq. (1) occurs sometime between $1 / 2$ and $1 \mathrm{~h}$ of MA.

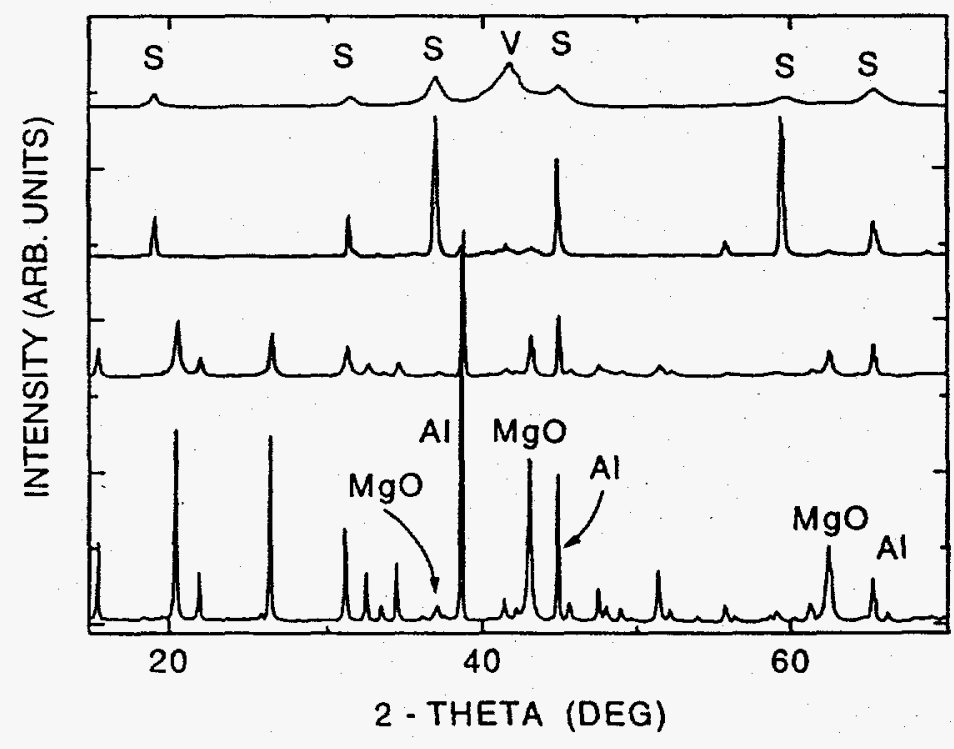

(d)

(b)

(a)
Fig. 1. X-ray diffraction patterns during the synthesis of the VSHP alloy powder. (a): initial mixture of $\mathrm{V}_{2} \mathrm{O}_{5}$ (all unlabeled Bragg peaks), $\mathrm{MgO}$, and Al. (b): after $0.5 \mathrm{~h}$ of MA. (c): after $1 \mathrm{~h}$ of MA. (d): after $10 \mathrm{~h}$ of MA. 
The VSLP and VSHP powders were loaded into tantalum cans which were then evacuated and sealed by e-beam welding. The cans were hot isostatic pressed at $0.2 \mathrm{MPa}$ and $1350^{\circ} \mathrm{C}$, keeping at pressure for $45 \mathrm{~min}$. The products were rods, $2-\mathrm{cm}$ diam. and $5 \mathrm{~cm}$ long. Samples were cut from the compacts using a water-cooled high-speed diamond impregnated saw.

The polished surfaces were examined by scanning electron microscopy. The same surfaces were studied by $x$-ray diffraction. The $x$-ray spectra weredeconvoluted using the Los Alamos GSAS Rietveld analysis routine. Hardness measurements were done using a diamond Vickers indenter. The toughness of the samples was deduced from the length of the radial cracks that formed at the corners of the Vickers indents for loads ranging from 10 to $30 \mathrm{~N}$. The elastic constants of the alloys were measured by a resonant ultrasound spectroscopy (RUS) technique [4]. The RUS data indicated that the two-phase alloys were isotropic and gave the values for the two independent elastic moduli.

\section{RESULTS}

Figure 2 is a SEM micrograph of the VSHP alloy. The vanadium appears as the light phase and the spinel as the dark phase. The pyramidal depression at the lower right of the figure was formed by the Vickers indenting probe. Two out of the four radial cracks extending from the corners of the indent are also visible. The horizontal crack runs straight, without encountering any large vanadium precipitates. The vertical crack, however, is observed to change direction at various places, whenever it encounters a large vanadium particle. This indicates that the vanadium phase is contributing to the toughening of the composite. The cracks do not seek the V-spinel interfaces which appear to be at least as strong as the matrix.

The toughness of the composites was determined from the length of the surface radial cracks.[5] The advantages of this technique (simplicity; applicable to small samples) are offset by various complications. The major problems are: (1) the accuracy to which the cracks can be 


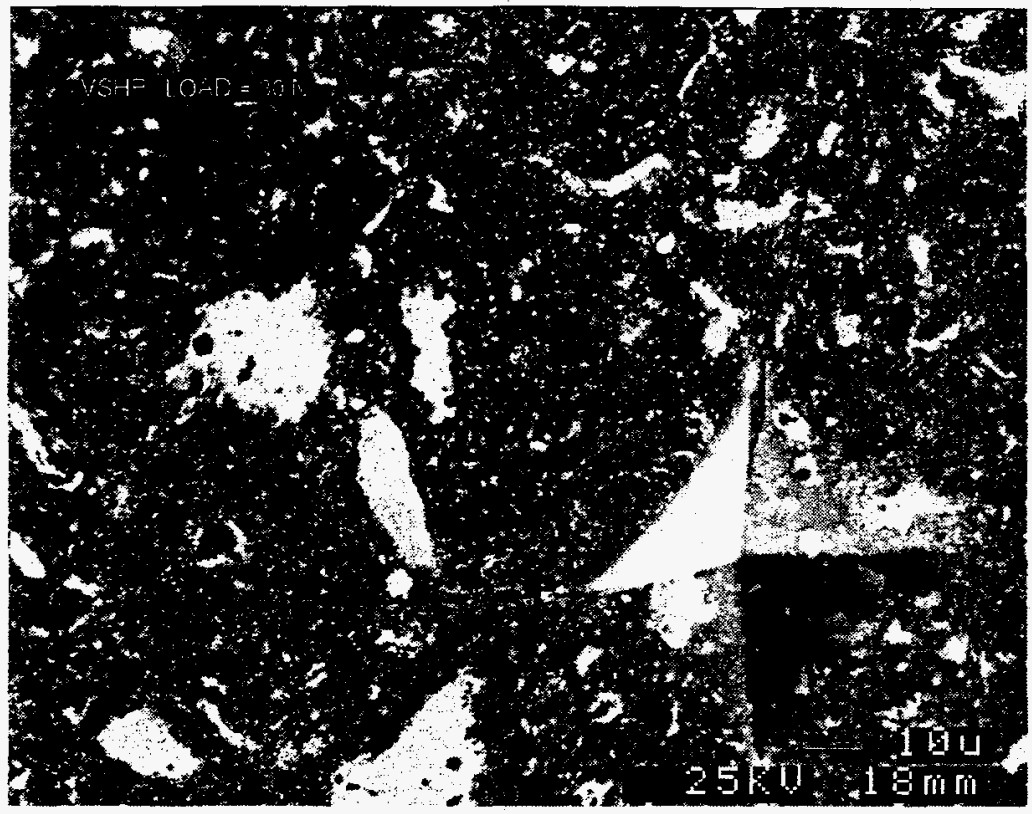

measured, and (2) the assumption that the sub-surface cracks are either one or the other of two idealized crack systems (the 'penny-shaped median' or the “Palmquist' types), which may or may not be the case for the material in question.

Fig. 2. SEM micrograph of the VSHP sample.

For the present samples, we analyzed the data using theoretical models deduced for both crack systems. For the 'penny-shaped median' crack type we used the model of Anstis et al. [6] which predicts, $K_{\mathrm{c}}=0.016(E / H)^{1 / 2}\left[P /(l+a)^{3 / 2}\right]$, where $E$ is the Young's modulus, $H$ the hardness, $P$ the load, $l$ the average crack length, and $a$ is half the diagonal of the indent. For the 'Palmquist' crack type we used the model of Niihara et al.[7], as modified by Srinivasan et al. [8], which predicts $K_{\mathrm{c}}=0.0123(E)^{0.4}(H)^{0.1}(P / l)^{1 / 2}$. The indentations were obtained for loads of 10 to $30 \mathrm{~N}$, in increments of $4 \mathrm{~N}$. Ten indents were made at each load and the crack lengths were measured from calibrated optical micrographs. The hardness was deduced from linear fits to load vs. (indent-area) plots. The Young's moduli were deduced from the RUS elastic moduli measurements.

Table I summarizes the mechanical properties of the two $20 / 80$ vanadium-spinel composites prepared in this work, as well as those of one of the previous $50 / 50$ vanadium spinel composite [2]. The elastic properties and hardness of the VSLP and VSHP composites are quite similar. The VSHP alloy has a slightly higher toughness than the VSLP alloy. Both alloys, 
however, have higher toughness than the large-grain VS-3 alloy studied previously [2]. This is significant in view of the fact that the present composites have much less vanadium. Although the toughness of monolithic spinel is only $\approx 1.4 \mathrm{MPa} \mathrm{m}{ }^{1 / 2}[9]$, the measured toughness of the VSHP composite, close to $4 \mathrm{MPa} \mathrm{m}^{1 / 2}$, is still too low for its intended application as structural material.

Table I. Mechanical Properties of Vanadium-Spinel Composites

\begin{tabular}{|c|c|c|c|c|c|c|c|}
\hline $\begin{array}{c}\text { Sample ID } \\
(\mathrm{V} / \text { spinel }) \\
\text { Vol. \% }\end{array}$ & $\begin{array}{c}E \\
(\mathrm{GPa})\end{array}$ & $\begin{array}{c}G \\
(\mathrm{GPa})\end{array}$ & $v$ & $\begin{array}{c}H \\
(\mathrm{GPa})\end{array}$ & $\begin{array}{c}K_{\mathrm{c}} \\
\left(\mathrm{MPa} \mathrm{m}^{1 / 2}\right) \\
\mathrm{Median} \\
\text { model } \\
\text { Eq. (2) }\end{array}$ & $\begin{array}{c}K_{\mathrm{c}} \\
\left(\mathrm{MPa} \mathrm{m}^{1 / 2}\right) \\
\text { Palmquist } \\
\text { model } \\
\text { Eq. (3) }\end{array}$ & $\begin{array}{c}K_{1 \mathrm{c}} \\
\left(\mathrm{MPa} \mathrm{m}^{1 / 2}\right) \\
\text { Chevron }_{\text {notch }} \\
(\text { Ref. [10]) }\end{array}$ \\
\hline $\begin{array}{c}\text { VSLP } \\
(20 / 80)\end{array}$ & 249 & 97.4 & 0.28 & 12.4 & 3.24 & 3.37 & \\
\hline $\begin{array}{c}\text { VSHP } \\
(20 / 80)\end{array}$ & 249 & 95.9 & 0.29 & 12.1 & 3.90 & 3.94 & \\
\hline $\begin{array}{c}\text { VS-3 } \\
(50 / 50)\end{array}$ & 270 & - & 0.27 & 4.7 & & & 2.66 \\
\hline
\end{tabular}

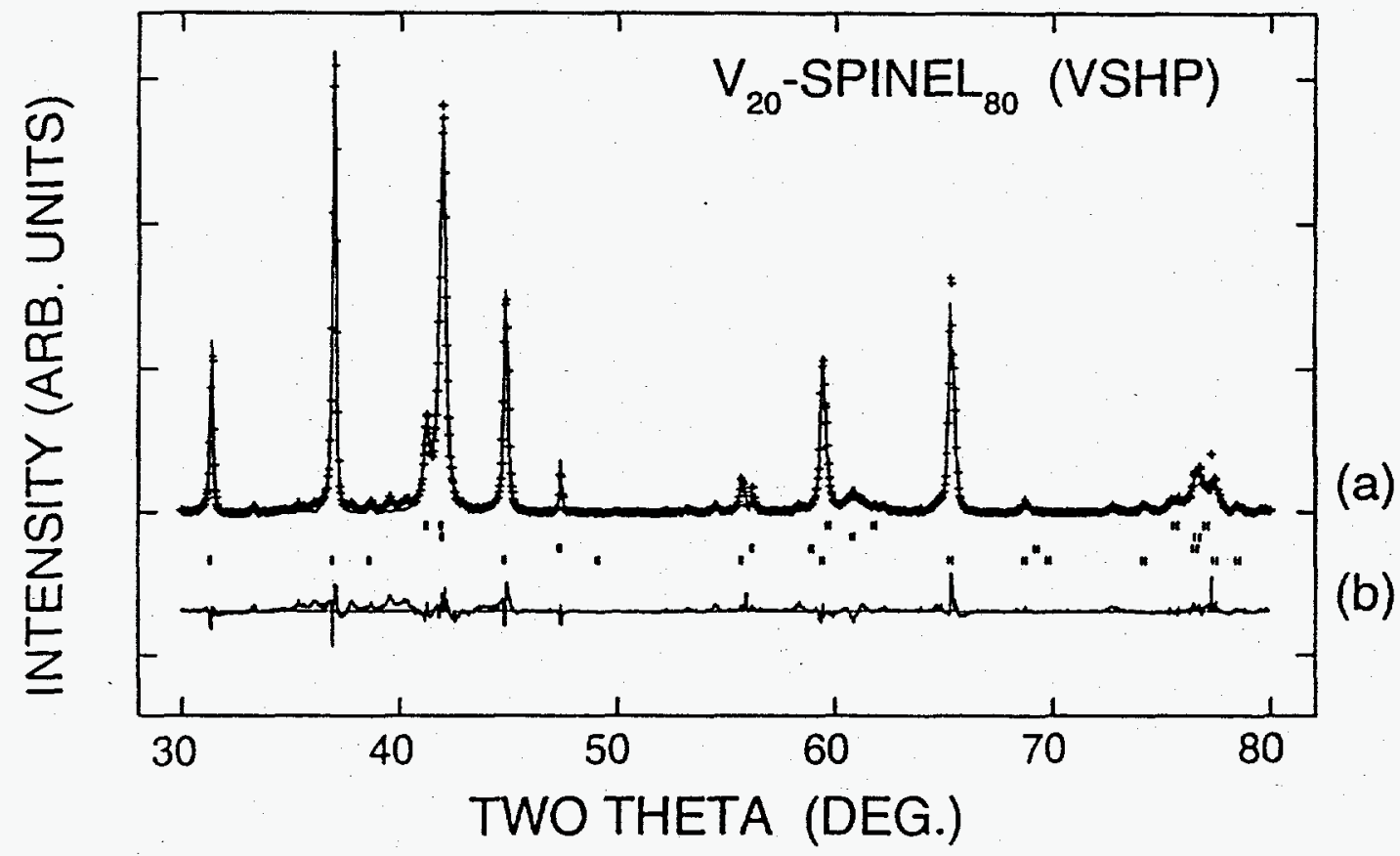

Fig. 3. Curve (a): $\mathrm{X}$-ray diffraction $(\mathrm{Cu}, \mathrm{K} \alpha)$ pattern from the VSHP composite. Curve (b): difference between the curve (a) and the Rietveld analysis fit (on an 100x expanded scale). 
The reasons for the low toughness become apparent when we analyze the $\mathrm{x}$-ray diffraction data. Fig. 3 shows the x-ray diffraction pattern and Rietveld fit for the VSHP sample. A similar refinement was obtained for the VSLP sample. Notice that the (200) Bragg peak of vanadium is split. This indicates that the vanadium is present both in the bcc and bet structures. The bct phase is stabilized by oxygen.[11] The Rietveld analysis enabled us to estimate the volume fraction of both phases and the results are given in Table II. The refinement also provided accurate values for the lattice parameters of the two vanadium phases. The interstitial oxygen in the bcc phase was deduced from the measured lattice parameter and the data of Henry et al.[12] For both alloys, the calculated oxygen content were close to 4 at $\%$, and this agrees with the room-temperature equilibrium value for bcc vanadium in equilibrium with the bct $V_{9} O$ phase.[11] Using the data in Table II we deduced the average oxygen content in the vanadium phase to be 6.7 and 5.8 at.\% for the VSLP and VSHP alloys, respectively. This compares favorably with the 15 to 20 at.\% oxygen content in the vanadium of the previous alloys [2].

Table II. Results of the Rietveld refinement of the x-ray diffraction data

\begin{tabular}{|c|c|c|c|c|}
\hline $\begin{array}{c}\text { Sample ID } \\
(\mathrm{V} / \text { spinel }) \\
\text { Vol. \% }\end{array}$ & Vol. \% bcc $V$ & $\begin{array}{c}\text { Vol \% bct } V \\
(V, O)\end{array}$ & $\begin{array}{c}a \text { for bcc V } \\
(\mathrm{nm})\end{array}$ & $\begin{array}{c}\text { Average } O \\
\text { content in } V \\
(\text { at. \%) }\end{array}$ \\
\hline $\begin{array}{c}\text { VSLP } \\
(20 / 80)\end{array}$ & 46 & 54 & 0.3047 & 6.7 \\
\hline $\begin{array}{c}\text { VSHP } \\
(20 / 80)\end{array}$ & 64 & 36 & 0.3043 & 5.8 \\
\hline $\begin{array}{c}\text { VS-1 } \\
(50 / 50) \\
(\text { Ref. xxx })\end{array}$ & 0 & 100 & - & 15 to 20 \\
\hline
\end{tabular}

\section{DISCUSSION}

The main goal of using the MA synthesis route was to increase the toughness of the Vspinel composites over the value previously obtained by hot pressing a 50/50 mixture of 
commercial powders. Although the present $20 / 80$ alloys contain much less vanadium, their toughness is higher by a factor of about 3. The increase is most likely due to (a) a better distribution of the vanadium phase as sub-micron size domains and (b) a lower oxygen content in the $\mathrm{V}$ phase. The VSHP alloys prepared by a novel reaction synthesis route is especially promising since it resulted in the lower content of oxygen in the vanadium phase. Future work will address the synthesis of $\mathrm{V}$-spinel composites in the presence of excess aluminum and/or magnesium, which we expect will further reduce the oxygen content and increase the toughness of the composites.

Acknowledgement: This work was supported by the US Department of Energy. Office of Basic Energy Sciences.

\section{DISCLAIMER}

This report was prepared as an account of work sponsored by an agency of the United States Government. Neither the United States Government nor any agency thereof, nor any of their employees, makes any warranty, express or implied, or assumes any legal liability or responsibility for the accuracy, completeness, or usefulness of any information, apparatus, product, or process disclosed, or represents that its use would not infringe privately owned rights. Reference herein to any specific commercial product, process, or service by trade name, trademark, manufacturer, or otherwise does not necessarily constitute or imply its endorsement, recommendation, or favoring by the United States Government or any agency thereof. The views and opinions of authors expressed herein do not necessarily state or reflect those of the United States Government or any agency thereof. 


\section{REFERENCES}

1. K. E. Sickafus, R. Raj, and P. C. Panda, Los Alamos National Laboratory publication LAUR-96-1183.

2. E. Ustundag, K. E. Sickafus, Y. He, R. B. Schwarz, P. C. Panda, and R. Raj, in Advances in Ceramic Matrix Composites, edited by N. P. Bansal. Ceramic Transactions, Vol. 74 (Amer. Ceram. Soc., Westerville, OH), in press.

3 D. L Harrod and R. E. Gold, Inter. Met. Rev. 25 (1980) 163-221.

4. A. Migliori, J. L Sarrao, W. M. Visscher, T. M. Bell, M. Lei, Z. Fisk, and R. G. Leisure, Phusica B 183 (1993) 1.

5 C. B. Ponton and R. D. Rawlings, Mater. Sci. and Tech. 5 (1989) 865-871. Ibid, pp. 961976.

6. G. R. Anstis, P. Chantikul, B. R. Lawn, and D. B. Marshall, J. Amer. Ceram. Soc. 64 (1981) $533-538$.

7. K. Niihara, R. Morena, and D. P. H. Hasselman, J. Mater. Sci. Lett. 1 (1982) 13.

8. S. Srinivasan and R. O. Scattergood, J. Am. Ceram. Soc. 74 (1991) 887-888.

9. R. W. Rice, F. W. Freiman, and J. J. Mecholsky, J. Amer. Ceram. Soc.63 (1980) 129-136.

10. J. H. Underwood, S. W. Freiman, and F. I. Baratta (eds.), Chevron-Notched Specimens: Testing and Stress Analysis, ASTM STP 855 (Amer. Soc. For Testing and Materials, Philadelphia, 1984).

11. Binary Alloy Phase Diagrams, Edited by T. B.Massalski, H. Okamoto, P. R. Subramanian, and L. Kacprzak (ASM, Metals Park, Ohio, 1990), Second Edition.

12. J. L Henry, S. A. O'Hare, R. A. McCune, and M. P. Krug, J. Less Common Met. 21 (1970) 115-135. 